\title{
The techniques of artificial breeding and fry rearing of Murray cod (Macculochella peelii) in China
}

\author{
Ziming Zhao *, Meijian Liu, Sheng Yuan, Sunan Chen, Xianglong Zheng \\ Jiangsu Agri-animal Husbandry Vocational College, Jiangsu Taizhou, 225300, China. \\ *Corresponding Author’s e-mail: zzm282678@163.com
}

Keywords: Macculochella peelii; artificial inducing; insemination; fingerling culture.

\begin{abstract}
China, Murray cod (Macculochella peelii) has attracted much attention. In order to improve the culture benefit, This Article is concentrated on the artificial breeding and fry rearing techniques of Murray cod, including the selection and culture of parent fish, artificial inducing, insemination, hatching, the feeding start time for the fry, food switching, domestication and fish seed culture. This is a reference for the majority of breeding workers.
\end{abstract}

Murray cod is endemic to the Murray-Darling River System, and it tops the four economic fishes in Australia and it is one of the largest freshwater fish in the world. The meat of Macculochella peelii is tender, delicious and thick, and there are few fish bones between muscles. It also contains 4 kinds of amino acids, EPA, DHA and other nutrients. It is high in protein and low in fat, so it is popular among the people. However, due to overfishing, environmental pollution and destruction of spawning grounds, its resource is decreasing day by day. Australia calls it the national treasure fish. Macculochella peelii has the characteristics of fast growth, strong adaptability to environment, high fecundity and survival rate, great disease-resistant ability, easy domestication and high conversion rate of artificial compound feed, so it is suitable for intensive culture in different culture areas [1]. In 1999, it was first introduced to Taiwan from Australia, and in 2001, it was introduced to the mainland of China [2]. At present, as a new breed of freshwater culture in China, the fish has attracted much attention and has great prospects for development. There are many related researches on Macculochella peelii[3-9]. This paper mainly introduces the industrialized artificial breeding technology of Macculochella peelii in China.

\section{Artificial breeding}

\subsection{Selection and culture of parent fish}

The sexual maturity time of Macculochella peelii is 3-5 years old, and generally, more than 70\% of the 4-year-old fishes are mature, the spawning is one batch a year, and the suitable water temperature is $16-20^{\circ} \mathrm{C}$. Through the study, we found that under the same conditions, the breeding effect of the parent fish over the age of 6 was better than that of the parent fish at the younger age. We should choose the healthy fish without disease or injury and the body color should be normal. The weight of male is $4 \sim 10 \mathrm{~kg}$, the weight of female is $5 \sim 10 \mathrm{~kg}$, and the ratio of male to female is $1 \sim 2: 1$. The selection of parent fish usually starts in autumn, and it needs about half a year of artificial intensive culture. We need to provide sufficient high protein feed, adjust the fat ratio, add vitamin C, vitamin E, n-3 HUFA and liver-protection products. The nutritional requirements of the parent fish vary with the water temperature. In autumn (September to November), when the water temperature is suitable, the protein required for nutrition is $\geqq 45 \%$ and the fat required for nutrition is $\geqq 15 \%$; in winter (December to February), when the water temperature is lower than $13^{\circ} \mathrm{C}$, the nutrition demand is high protein and low fat, and the proportion of fat is reduced. In spring (March to May), the water temperature is suitable, and the nutrition demand is maintained by low protein and low fat. There is a certain relationship between gonad development and water temperature (Fig. 1) [10]. 


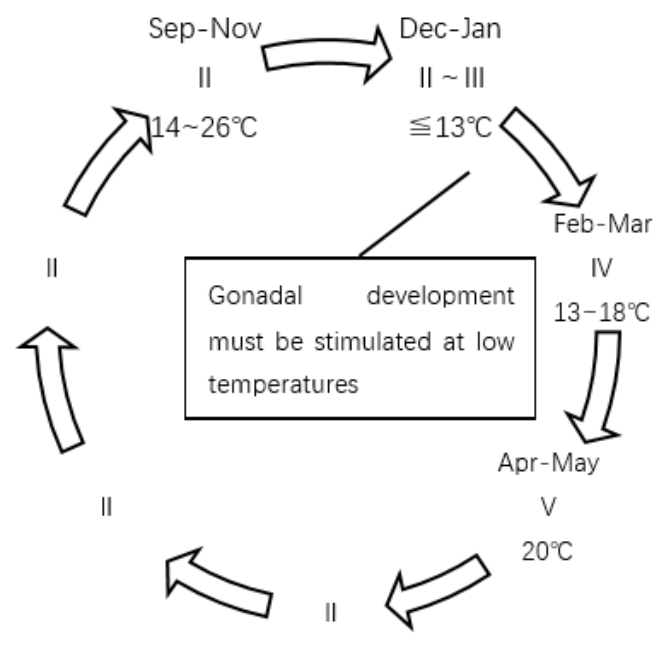

Fig. 1. The relationship between gonad development and water temperature

In autumn (September to November), the water temperature is suitable, the gonad is in the II stage, and the gonad can develop to the III stage only after low temperature stimulation. Under $13 \sim 18{ }^{\circ} \mathrm{C}$, it is in stage IV, and after the water temperature reaches $20^{\circ} \mathrm{C}$ for one week, it can be in the V stage. At this time, the abdomen of the parent fish expands, and the female's genital pore is dark red or purple. We use a glass tube with a diameter of $4 \mathrm{~mm}$ to export the egg for microscopical examination, and it can be found that the egg is an amber and translucent ball, with a diameter of about $3 \mathrm{~mm}$. From the head to the tail, we push the abdomen of the male fish, and we can squeeze out the semen. After it is diluted by normal saline, we carry out microscopic examination to check the sperm density and viscosity, then we choose the male with good sperm quality as the parent sample. After stress operation such as fishing, the gonad development of the sexually mature parent fish will go through the process of degeneration and absorption, and the ovary contains yolk and primary oocyte, so it is not suitable to carry out fishing before artificial inducing [11].

\subsection{Artificial inducing}

In the process of artificial inducing, the most commonly used Pitocin is HCG or CPG, and the normal saline is prepared on site and then used on site. Use normal saline to dissolve the drug, and the dosage for each tail is not more than $5 \mathrm{ml}$, and then inject HCG 900-1000 IU per kg or HCG200 IU+CPG $5 \mathrm{mg}$ per kg into to female fish, while for male fish, the dosage is halved. Before catching the parent fish, we first use eugenol $10 \mathrm{ml} / \mathrm{m} 3$ to anesthetize it, and then catch the fish, and then finish the injection within one hour. The injection position is the base of ventral fin or the base of pectoral fin. After injection, in order to prevent them from chasing and biting, we must put them in the birth pond alone. When the water temperature is $20 \sim 21^{\circ} \mathrm{C}[12]$, we inject HCG $1000 \mathrm{IU}$ per $\mathrm{kg}$. After $46 \sim 48$ hours, they begin to ovulate. 2 3 hours after ovulation, we extrude the eggs and inseminate them, and the hatchability is $85.5 \% \sim 90 \%$; after $45 \sim 46$ hours, we extrude the eggs and inseminate them, the hatchability is $70 \% \sim 89 \%$. The meiosis of different fish eggs is different. Within one hour after ovulation, the eggs may not reach the meiosis stage, and after three hours, the eggs may have passed the meiosis stage, which will greatly reduce the hatchability. 


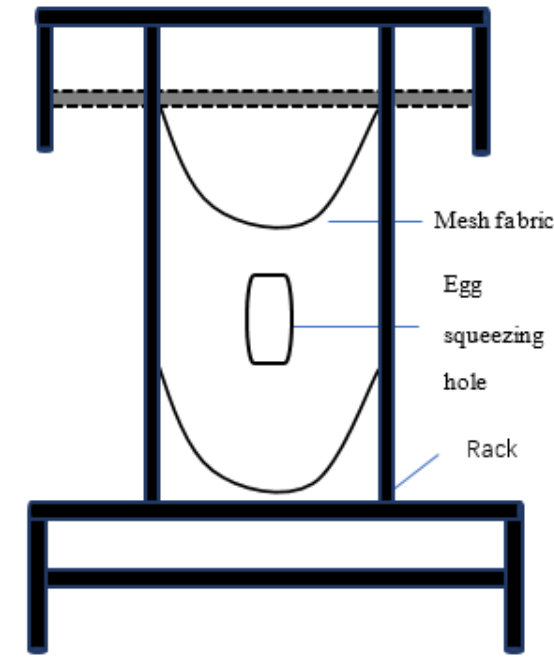

Fig 2. Diagram of spawning rack

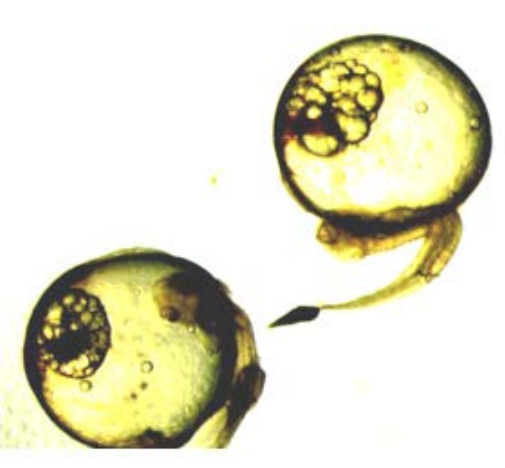

Fig 3. Newly hatched fry

\subsection{Insemination and hatching}

Before spawning of fish, we use eugenol to immerse the parent fish to anesthetize it ${ }^{[13]}$, then catch it, clean it with water, and use towel to dry the water on the body surface. In order to prevent the parent fish body surface from being injured during egg squeezing, please use plastic wrap to wrap the abdomen in front of the female's genital pore, and let the abdomen face down and then put it into the spawning rack (Fig. 2), and then squeeze the eggs from head to tail. The scales on the surface of the fish are thin and soft, which are easy to fall off. In the process of egg squeezing, it is easy to cause damage on the body surface or even death. We can disinfect the body surface with iodine solution and inject Penicillin $10000 \mathrm{IU} / \mathrm{kg}$. Note that in each operation, only 10000-15000 eggs can be squeezed. Taking a $6.71 \mathrm{~kg}$ female as an example, there are still 103.8g mature eggs in the body, about 3824 eggs, which will be naturally excreted to the outside of the body the next day.

Use a plastic basin with smooth surface to collect eggs. The plastic basin contains the mixed solution of $500 \mathrm{ml} 0.9 \%$ normal saline and $500 \mathrm{ml} 5 \%$ glucose. Quickly rotate the basin to prevent eggs from adhesion. At the same time, let the male's abdomen be upward, use clean water to dry the body surface water, squeeze and extract semen. After the semen is diluted by $5 \%$ glucose injection, put it in the plastic basin to combine with the eggs, mix well and let the eggs inseminate. After 3-5 minutes, use clear water to rinse the fertilized eggs for 3-4 times to remove mucus, and then put the fertilized eggs are into a plastic basin with nylon gauze to let them adhere to the surface of the gauze. After 10-15 minutes, gently pick up the gauze and transfer it into the incubator for hanging and hatching. The flow of water for hatching is $4 \sim 5 \mathrm{~L} / \mathrm{min}$. During hatching, we should check the hatching progress of the eggs at any time. The normally developed eggs are in the shape of transparent pearls, in the color of cream, while the undeveloped eggs are in the white and opaque color.

The incubation time of the fertilized eggs is closely related to the water temperature. The water temperature is $19 \sim 21^{\circ} \mathrm{C}$, and the spots will appear on the fertilized eggs after 4-5 days. They start to hatch on the 5th day (Fig. 3), most on the 7th day, and all on the 8th day. Before the fish emerge from the membrane, use $100 \mathrm{ml} / \mathrm{m} 3$ formaldehyde to disinfect the fertilized eggs once a day to prevent saprolegniasis and parasitic infection and improve the hatching rate.

\section{Fingerling culture}

Facilities and conditions for fingerling culture. In the fry stage, the Macculochella peelii likes shade and is afraid of light. We use black fiberglass to block the light of the culture ponds. Among the culture ponds of the industrialized circulating water culture system, there are round culture ponds, in which the flow rate should not be too fast, so that we can observe the movement and development of the fish, and it also facilitates the sewage discharge, which make the survival rate of the fry higher. Each culture pond is an independent culture unit. Dozens of culture units are set up in parallel to 
facilitate our efficient management and operation for a single culture pond, realize the industrialized management for fry culture, improve production efficiency and benefit, reduce the probability of disease transmission and infection and improve the survival rate. The daily new water supply of the water inlet and drainage treatment system accounts for $8 \% \sim 10 \%$ of the total water in the culture pond, which helps to save $90 \%$ of the water consumption and greatly reduces the energy consumed by temperature control by about $70 \%$. Water quality conditions: water temperature is $18 \sim 21^{\circ} \mathrm{C}, \mathrm{pH}$ is 7.5 8.5, dissolved oxygen content is above $6 \mathrm{mg} / \mathrm{L}$, ammonia nitrogen (NH3-N) $<0.01 \mathrm{mg} / \mathrm{L}$, nitrite (NO2--N) $<0.1 \mathrm{mg} / \mathrm{L}$, sulfide $<0.2 \mathrm{mg} / \mathrm{L}$ [14]. The fry culture is phased. The specific process is as follows.

\subsection{The feeding start time for fry and the breeding}

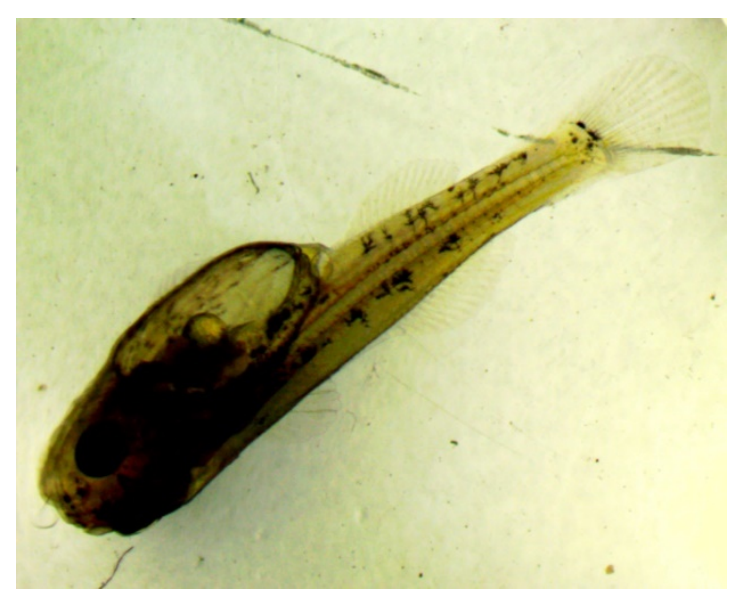

Fig 4. Yolk plug of Macculochella

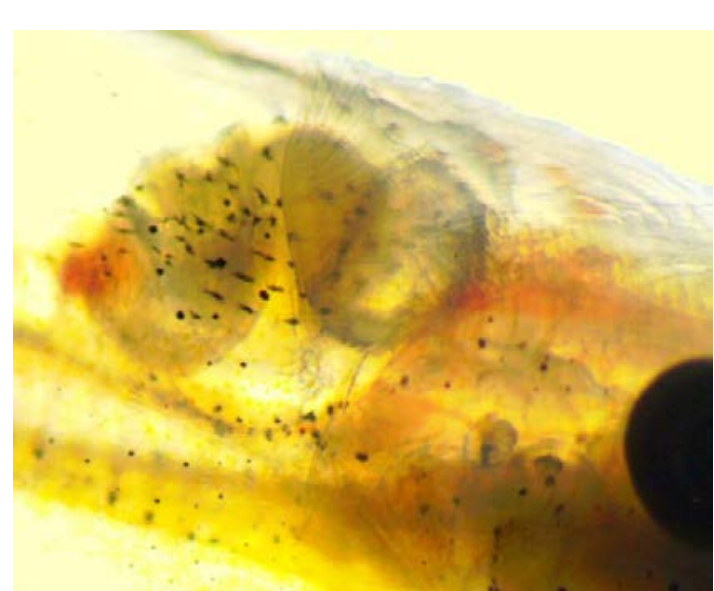

Fig 5. Inflatable swim bladder of Murray cod

As for the culture of $0 \sim 15$-day-old fry, the fry hatched on March 26th were put into a circular culture pond $(2.0 \mathrm{~m} \times 0.6 \mathrm{~m} \times 0.4 \mathrm{~m})$, and the water level is $0.6 \sim 0.7 \mathrm{~m}$. The stocking density of Macculochella peelii is 23000 28000 fish $/ \mathrm{m}^{2}$. The fry hatched on March 26th, at the water temperature of $19 \sim 20^{\circ} \mathrm{C}$, started to eat things on April 9th. There are four characteristics of the start of eating, one is the disappearance of yolk sac, the second is the opening of mouth and the appearance of yolk plug at anus (Fig 4), the third is that there is an obviously inflated swim bladder on the left side of the fry (not obvious on the right side) (Fig 5), and the fourth is that the fry starts to move from centralized distribution to scattered distribution. We can choose the animal feed, fairy shrimp, as the initial feeding bait. The feeding amount is roughly the same as the weight of the fry. The feeding frequency is $10 \sim 15$ times a day. After the fry is put into the pond, increase the water temperature by $2 \sim 3{ }^{\circ} \mathrm{C}$, which can quicken the start time of eating. The survival rate of the fry is more than 95\%[15]. At the end of culture, the total length of larvae was $1.2 \sim 1.5 \mathrm{~cm}$, and the weight was $0.2 \sim 0.5 \mathrm{~g}$.

Transfer the 15 30-day old fry into a circular culture pond (diameter $1.0 \mathrm{~m} \times$ height $1.0 \mathrm{~m}$ ). The water level in the pond was controlled at $0.8 \mathrm{~m}$. Feed the fry 10 14 times a day with the fairy shrimp, and the feeding weight accounted for $45 \% \sim 55 \%$ of the total fry weight. At the end of the culture, the larvae were $1.5 \sim 1.9 \mathrm{~cm}$ in length and $0.8 \sim 1.4 \mathrm{~g}$ in weight.

\subsection{The food switching and domestication of fry}

We mainly feed the mixture of animal feed (fairy shrimp) and artificial compound feed (No.0 feed). The stocking density of fry is $1 \sim 12$ thousand $/ \mathrm{m}^{2}$. In the stage of the food switching and domestication of fry, we mainly feed it with the fairy shrimp and domesticate it until the feed needed is mainly the mixed feed, and the feeding frequency is 10 14 times a day. The mixed feed includes animal feed and artificial compound feed. The protein content of artificial compound feed is $45 \% \sim 55 \%$, the fat content is $15 \% \sim 25 \%$, the additive amount of mineral compound content is $8 \% \sim 10 \%$, and the additive amount of vitamin content is $2 \% \sim 5 \%$. When we feed it with the mixed feed, according to the proportion of $10 \%$ 20\% of the original feeding amount, we, day by day, reduce the feeding amount of 
the animal feed to 0 , while the feeding amount of the artificial compound feed is increased day by day, and the final feeding amount accounts for 10\% 20\%; the original feeding amount of the animal feed accounts for $45 \% \sim 55 \%$ of the total weight of the fry, and the final feeding amount of the artificial compound feed accounts for $4 \% \sim 6 \%$ of the total weight of the fry[16]. In the process of domestication, we should pay attention it that we should adjust the feeding quantity according to the feeding condition of the fish species. At this stage, when the body length of the fry is $3 \mathrm{~cm}$, we need to grade the fry according to its body length to prevent fish of different specifications from eating each other, and at the same time, we need to eliminate the obviously weak and deformed young fish. Before we grade it, let the young fish eat nothing for one day to reduce the stress response of young fish.

\subsection{Large-size fry breeding}

This stage is mainly aimed at the 45 90-day old fry. Transfer the fry into a circular culture pond (diameter $2.0 \mathrm{~m} \times$ height $1.3 \mathrm{~m}$ ). The water level in the culture pond is controlled at $0.8 \sim 1.2 \mathrm{~m}$, and the density of the fry put into the culture pond is 5000 7000 pieces $/ \mathrm{m}^{2}$. During this stage, completely feed the artificial compound feed 10 12 times a day, and the daily feeding amount accounts for 3\% 4\% of the total weight of the fry. After this stage, the size of the cultured fry reached $10 \sim 12 \mathrm{~cm}$ and the weight are $30 \sim 40 \mathrm{~g}$. In order to strengthen the body constitution of fry, improve the hypoxia tolerance and the anti-stress ability, we should classify the fry according to body length, and eliminate the obviously weak and deformed fry. The survival rate of fry at this stage reaches $90 \%$.

\subsection{Fingerling breeding}

The breeding period of this stage is 40-60 days. Transfer the fry into a circular culture pond (diameter $2.0 \mathrm{~m} \times$ height $1.3 \mathrm{~m}$ ). The bottom of the pond is inclined to the center, and the slope is $3 \%$. In the center of the pond, there is a drain hole with a diameter of $15 \mathrm{~cm}$. The water level in the culture pond is controlled at $1.1 \sim 1.3 \mathrm{~m}$, and the breeding density of the fry in the culture pond is 300-400 pieces $/ \mathrm{m}^{2}$. Completely feed the artificial compound feed 10 12 times a day, and the daily feeding amount accounts for 3\% 4\% of the total weight of the fry. Every day, we need to drain the fry culture pond, and the times of contamination drain are equal to the times of feeding. During the period when the average body length of the fry is $10 \sim 15 \mathrm{~cm}$, we need to grade the fry every 20 days, and then the interval days of the fry grading gradually increase until the average body length of the fry reaches $15 \mathrm{~cm}$. Separate the fry of different specifications according to the different sizes of the sieve holes on the fry-separating sieve. After 40-60 days of culture, we can get fish species with an average weight of $70 \sim 100 \mathrm{~g}$, and then we can carry out large-scale industrial breeding of Macculochella peelii.

\section{Acknowledgments}

This research was financially supported by “Jiangsu Three New Engineering’s” (Grant No. Y2017-42) and "Quality engineering construction project of Jiangsu Agri-animal Husbandry Vocational College” (Grant No. 201912806027Y).

Conflict of Interest: The authors declare that they have no conflict of interest.

Ethical approval: "All applicable international, national, and/or institutional guidelines for the care and use of animals were followed by the authors.”

\section{References}

[1] Ay, R \& Rowland, Stuart. (2005). Overview of the history, fishery, biology and aquaculture of Murray cod (Maccullochella peelii peelii). Management of Murray Cod in the Murray-Darling Basin: Statement, Recommendations and Supporting Papers. 
[2] WENG B Q, LUO T Y, LIU Y, et al. Biological Characteristics, Propagation and Aquaculture of Murray Cod (Maccullochellapeelii) [J]. Fujian Journal of Agricultural Sciences, 2016, 31(01):89-94.

[3] David S. Francis, Giovanni M. Turchini, Paul L. Jones, et al. Effects of dietary oil source on growth and fillet fatty acid composition of Murray cod, Maccullochella peelii peelii[J]. Aquaculture, 2006,253(1-4):0-556.

[4] R M. Gunasekera, S S. De Silva, R A. Collins, et al. Effect of dietary protein level on growth and food utilization in juvenile Murray cod Maccullochella peelii peelii (Mitchell)[J]. Aquaculture Research, 2000, 31.

[5] David S Francis, Giovanni M Turchini, Paul L Jones,等. Dietary Lipid Source Modulates in Vivo Fatty Acid Metabolism in the Freshwater Fish, Murray Cod ( Maccullochella peelii peelii )[J]. Journal of Agricultural \& Food Chemistry, 2007, 55(4):1582-1591.

[6] David S Francis, Giovanni M Turchini, Paul L Jones, et al. Dietary Lipid Source Modulates in Vivo Fatty Acid Metabolism in the Freshwater Fish, Murray Cod ( Maccullochella peelii peelii )[J]. Journal of Agricultural \& Food Chemistry, 2007, 55(4):1582-1591.

[7] Go J, Lancaster M, Deece K, et al. The molecular epidemiology of iridovirus in Murray cod (Maccullochella peelii peelii) and dwarf gourami (Colisa lalia) from distant biogeographical regions suggests a link between trade in ornamental fish and emerging iridoviral diseases. [J]. 2006, 20(3):212-222.

[8] Ryan T, Ingram B A, Woakes A J, et al. Factorial aerobic scope is independent of temperature and primarily modulated by heart rate in exercising Murray cod (Maccullochella peelii peelii). [J]. 2005, 78(3):347-355.

[9] Paul Humphries. Spawning time and early life history of Murray cod (Maccullochella peelii Mitchell) in an Australian river[J]. Environmental Biology of Fishes, 72(4):393-407.

[10] YAN B B, GUO Z L, WEI W L. Large-scale breeding technology of [J]. Scientific Fish Farming, 2018, 352(12):14-15.

[11] CHEN Y l, ZHU X P, LIU Y H. Australian freshwater cod and artificial breeding [J]. Freshwater Fisheries, 1999 (7): 6-7

[12] GUO S, WANG G J, FANG Z S, et al. Biological characteristics and artificial propagation technology of Murray cod [J]. Jiangsu Agricultural Sciences, 2012(12):254-255.

[13] CHEN X J, XIONG L L, WU J G, et al. Effects of anesthetic eugenol on respiration and excretion of Sinogastromyzon szechuanensis[J]. J Phys Conf Ser. 2019,1423(1): 01004.

[14] Chen X J , Wang J , Zhu Y Y , et al. Test of intercropping myxocyprinus asiaticus in the eriocheir sinensis pond[J]. Advance Journal of Food Science \& Technology, 2013, 5(10):1361-1366.

[15] LI X L, CHEN T T, SU S P, et al. Industrialized seed breeding technology for Murray cod [J]. Scientific Fish Farming, 2019, 354(02):16-17.

[16] GUO Z L, YANG X Y, MENG Q Y. Industrialized farming technology for Murray cod [J]. Journal of Aquaculture, 2012, 34(12):39-40. 